\title{
PENGARUH PERSEPSI DUKUNGAN ORGANISASI DAN KEPRIBADIAN TERHADAP KEPUASAN KERJA GURU SD ISLAM AL AZHAR DI JAKARTA TIMUR
}

\begin{abstract}
Nasjudi. ${ }^{1}$
Abstract: The purpose of this research is to determine the effect of perceived organization support and personality on job satisfaction the teacher state primary school al azhar, East Jakarta. The research methodology was survey which were selected by simple random sampling technique. Analysis and interpretation of the data indicate that (1) perceived organization support has a positive direct effect in job satisfaction, (2) personality has a positive direct effect in job satisfaction, (3) perceived organization support has a positive direct effect in personality.
\end{abstract}

Keywords: perceived organization support, personality, job satisfaction.

\section{PENDAHULUAN}

Kualitas pendidikan di Indonesia saat ini sangat memprihatinkan. Ini dibuktikan dengan indeks pembangunan manusia (IPM) Indonesia sangat rendah. Menurut United Nations Development Program, IPM Indonesia tahun 2011 di urutan 124 dari 187 negara yang disurvei dengan skor 0,617 peringkat ini turun dari peringkat 108 pada tahun 2010 di kawasan ASEAN Indonesia hanya unggul dari Vietnam yang memiliki nilai IPM 0,593 Laos dengan nilai IPM 0,524 Kamboja dengan nilai IPM 0,523 dan Myanmar dengan nilai IPM 0,483 Di ASEAN peringkat pertama dalam hal kualitas manusia adalah Singapura dengan nilai 0,866 kemudian disusul Brunei dengan nilai IPM 0,838 disusul Malaysia 0,761 Thailand 0,682 dan Filipina 0,644 salah satu komponen yang dihitung dalam penghitungan IPM adalah rata-rata lamanya sekolah. Rendahnya IPM Indonesia ini menunjukkan dampak dari alokasi 20\% APBN untuk pendidikan ini belum terasa. Kualitas pendidikan di Indonesia saat ini sangat memprihatinkan. Ini dibuktikan dengan indeks pembangunan manusia (IPM) Indonesia sangat rendah. Menurut United Nations Development Program, IPM Indonesia tahun 2011 di urutan 124 dari 187 negara yang disurvei dengan skor 0,617 peringkat ini turun dari peringkat 108 pada tahun 2010 di kawasan ASEAN Indonesia hanya unggul dari Vietnam yang memiliki nilai IPM 0,593 Laos dengan nilai IPM 0,524 Kamboja dengan nilai IPM 0,523 dan Myanmar dengan nilai IPM 0,483 Di ASEAN peringkat pertama dalam hal kualitas manusia adalah Singapura dengan nilai 0,866 kemudian disusul Brunei dengan nilai IPM 0,838 disusul Malaysia 0,761 Thailand 0,682 dan Filipina 0,644 salah satu komponen yang dihitung dalam penghitungan IPM adalah rata-rata lamanya sekolah. Rendahnya IPM Indonesia ini menunjukkan dampak dari alokasi 20\% APBN untuk pendidikan ini belum terasa.

Pemeratan pendidikan, profesionalitas guru dan literasi bahasa menjadi kunci penting tercapainya pendidikan yang berkualitas di sebuah negara. Kesadaran inilah yang menjadikan Finlandia sukses sebagai pusat pendidikan nomor 1 dunia. Negara Indonesia harus bisa mencontoh Finlandia jika ingin menjadi negara maju, karena dengan pendidikan lah sebuah negara bisa menjadi maju dan berkembang. Berdasarkan data Programme for international student assesment (PISA) 2000, beberapa negara seperti Finlandia, Kanada, Selandia Baru, Australia, Irlandia, Korea Selatan, Inggris dan Jepang tercatat di peringkat teratas dalam hal literisasi membaca dan menulis. Kemudian pada

1 Staf Yayasan Pendidikan Indonesia. 
tahun 2006 Finlandia, Jepang, Kanada, Selandia Baru, dan Australia di kukuhkan lagi sebagai 5 besar negara dengan penguasaan ilmu pengetahuan tertinggi. Keunggulan mereka peroleh melalui pemerataan pendidikan.

Selaras dengan Visi dan Misi yayasan Al Azhar “Menjadi Lembaga Dakwah dan Pendidikan Islam terkemuka dan modern dalam mencerahkan dan mencerdaskan kehidupan bangsa guna membentuk masyarakat Indonesia yang beriman, berilmu, beramal, dan bertaqwa menuju izzul Islam wal muslimin". Diperkuat oleh wakil ketua Pembina Al azhar yaitu $\mathrm{H}$. Jimly Asshiddiqie, mengungkapkan bahwa setiap elemen dalam pendidikan harus saling terkait dan saling mendukung demi terwujudnya masyarakat yang beriman, berilmu, beramal dan bertaqwa, oleh sebab itu guru sebagai salah satu elemen terpenting dalam sekolah perlu memiliki sebuah kepribadian yang baik agar dapat menjadikan sebuah fiqure oleh murid-muridnya di dalam kehidupan sehari-hari di dalam lingkungan sekolah, dan tak kalah penting seorang guru harus dapat membuat atau mengambil sebuah keputusan yang tepat dan cepat di dalam setiap tindakannya dengan panduan norma-norma yang sudah ditetapkan oleh sekolah.Banyak jumlah guru yang ada pad setiap jenjang pendidikan dari tingkat dasar sampai menengah diharapkan mampu meningkatkan kualitas pendidikan di sekolah masing-masing. Salah satu hal yang dapat mendukung pencapai efektivitas dan efisiensi tujuan sekolah adalah guru diharapakan menampilkan kinerja yang baik dalam menjalankan tugas dan fungsinya sebagai pendidik dan mampu menampilkan perilaku diluar persyaratan kewajiban formalnya sebagai pendidik. Perilaku ini dikenal dengan organizational citizenship behavior (OCB).

Banyak faktor yang mengakibatkan guru tidak fokus kepada pekerjaannya, diantaranya dukungan organisasi sekolah, kepribadian guru itu sendiri dan diantaranya, masih sedikit perhatian baik dari sekolah atau dinas pendidikan setempat kepada guru itu sendiri, seperti pemenuhan kebutuhan fasilitas dalam belajar mengajar, masih banyak sekolah yang minim sarana dan prasarana yang dapat berdampak kepada berkurangnya kepuasaan kerja guru dalam mengajar. Diantaranya sekolah swasta yang memiliki image bahwa mereka menjadi sekolah sebuah ladang penghasil uang tanpa memikirkan mutu pendidikannya;

Ada beberapa kebijakan yang sudah cukup baik di lingkungan sekolah Al-Azhar Islam diantaranya dengan di berikannya uang transport, uang kerajinan kerja, uang makan, uang peralihan, bantuan pengobatan, uang pengganti cuti, hadiah pernikahan, bantuan bersalin, uang kelebihan jam mengajar, insentif dalam kampus, uang dinas dalam kota, uang perjalanan dinas luar kota, uang perjalanan dinas luar negeri, uang lembur, bantuan musibah, detasering, hadiah idul fitri, penghargaan, rekreasi, uang pesangon, uang jasa, jaminan hari tua. Kebijakan ini di buat demi meningkatkan kepuasaan kerja guru dengan tujuan akan meningkatkan mutu pendidikan sekolah di bawah naungan yayasan Organisasi pelajar islam. Ada beberapa antarnya guru yang masih merasa kepuasaan kerjanya masih kurang dikarenakan beban mengajar yang cukup banyak, tuntutan dari pihak sekolah kepada setiap guru terlalu tinggi yang berdampak kepada munculnya stres kerja guru. Hal-hal ini yang di usahakan untuk di minimalisir oleh setiap pimpinan sekolah.

Untuk meningkatkan kepuasan kerja guru diantaranya dilakukan oleh kepala sekolah dengan memahami kepribadian setiap guru. Kepribadian adalah sebuah ciri khusus yang melekat kepada setiap individu yang membedakan antara satu dengan yang lainnya. Kepribadian merupakan sebuah identitas diri yang ada disetiap manusia dan sulit untuk disama ratakan. Disinilah tugas utama setiap pimpinan untuk menemukan bagaimana cara untuk mengetahui dimana sisi kelemahan dan kelebihan 
setiap guru. Untuk memaksimalkan usaha pimpinan agar terciptanya suasana yang kondusif dan kepuasan bekerja guru akan meningkat.

Berdasarkan uraian tersebut, maka peneliti tertarik untuk melakukan penelitian dengan judul pengaruh persepsi dukungan organisasi, kepribadian terhadap kepuasan kerja guru Sekolah Dasar Islam Al Azhar di Jakarta Timur.

\section{Kepuasan Kerja}

Konsep kepuasan kerja menurut Laurie J. Mullins(2010:282) adalah konsep yang rumit, "job satisfaction is a complex and multifaceted concept, which can mean different things to different people". Karena menurutnya, kepuasan kerja dapat memiliki arti berbeda bagi masing-masing orang. Menurut Stephen P. Robbins, Timothy A. Judge (2013:74), “when people speak of employee attitudes, they usually mean job satisfaction, which describes a positive feeling about a job, resulting from an evaluation of its characteristics. A person with a high level of job satisfaction holds positive feelings abou this or her job, while a person with a low level holds negative feelings. Ketika orang membicarakan sikap pegawai, maka maksud mereka biasanya adalah kepuasan kerja, yang menggambarkan perasaan positif mengenai pekerjaan, hasil evaluasi berdasarkan karakteristik pekerjaannya. Seseorang dengan tingkat kepuasan kerja yang tinggi memiliki perasaan positif terhadap pekerjaannya dan sebaliknya seseorang yang memiliki tingkat kepuasan kerja rendah maka memiliki perasaan negatif terhadap pekerjaannya.

Begitu pula menurut Schermerhorn et.al (2011:72), kepuasan kerja merupakan sebuah sikap, "job satisfaction, an attitude reflecting a person's positive and negative feelings toward a job, co-workers and the work environment". Kepuasan kerja sebuah sikap yang mencerminkan perasaan positif atau negatif dari seseorang terhadap pekerjaan, rekan kerja dan lingkungan kerja. Kepuasan kerja merupakan salah satu faktor yang harus diperhatikan dalam upaya meningkatkan kinerja pegawai. Menurut John $R$. Schermerhorn (2011:388) mendefinisikan kepuasan kerja, "job satisfaction is the degree to which an individual feels positive or negative about various aspcets of work". Kepuasan kerja adalah sejauh mana seseorang merasa positif atau negatif tentang berbagai aspek pekerjaan. Pendapat yang hampir serupa dikemukakan oleh Stephen P. Robbins, Timothy A. Judge (2013:108) berpendapat bahwa, "job satisfaction is a positive feeling about a job resulting from an evaluation of its characteristics is clearly broad". Kepuasan kerja adalah perasaan positif tentang pekerjaan sebagai hasil dari evaluasi pada suatu karakter adalah jelas digambarkan. Menurut Jason Colquitt Jeffery A. Lepine and Michael J. Wesson (2015:98) menyatakan bahwa, "job satisfaction is defined as a pleasurable emotional state resulting from the appraisal of one's job or job experiences". Kepuasan kerja didefinisikan sebagai keadaan emosional yang menyenangkan yang dihasilkan dari penilaian dari pekerjaan atau pengalaman kerja.

Selanjutnya James L. Gibson, James H. Donnelly, Jr, John M. Ivancevich, Robert Konopaske (2012:102), "job satisfaction is an attitude that individuals have about their jobs. it results from their perceptions of their jobs, based on factors of the work environment, such as the supervisor style, policies and procedures, work group affiliation, working condition, and fringe benefits". Kepuasan kerja adalah sikap bahwa individu memiliki tentang pekerjaan mereka. itu hasil dari persepsi mereka tentang pekerjaan mereka, berdasarkan faktorfaktor lingkungan kerja, seperti gaya pengawas, kebijakan dan prosedur, afiliasi kelompok kerja, kondisi kerja, dan tunjangan. Selanjutnya Lussier (2013:64) mengatakan, "job satisfaction is a set of attitudes toward work, what most employees 
want from their jobs, even more than they want job security or higher pay". Kepuasan kerja sebagai sikap terhadap pekerjaan, apa yang menjadi keingan besar para pegawai dari pekerjaan mereka, bahkan lebih menginginkan keamanan kerja atau gaji yang lebih tinggi. Robert Kreitner, Angelo Kinicki (2010:170), "job satisfaction is an affective or emotional response toward various facets of one's job". Kepuasan kerja merupakan respon afektif atau emosional terhadap berbagai aspek pekerjaan seseorang. Pendapat yang hampir serupa di katakan oleh E. A Locke di dalam bukunya Steven L. Mc Shane, Mary Ann Von Glinov (2010:108) mengatakan bahwa, "job satisfaction a person evaluation of his her job and work context, is probably the most studied attitude in organizational behavior". Kepuasan kerja seseorang adalah evaluasi diri dari pekerjaannya dan konteks kerja, mungkin sikap yang paling banyak dirasakan dalam budaya organisasi.

Berdasarkan definisi konsep yang telah diuraikan dapat disintesiskan kepuasan kerja adalah respon emosional terhadap pekerjaan dan pengalaman kerjanya dalam sebuah organisasi dengan indikator: perasaan terhadap pekerjaan, perasaan terhadap rekan kerja, perasaan terhadap penghargaan, perasaan terhadap tanggung jawab dan perasaan terhadap mengembangkan diri.

\section{Persepsi Dukungan Organisasi}

Jason Colquitt, Jeffery A. Lepine, Michael J. Wesson (2015:82), “perceived organizational support reflects the degree to which employees believe that the organizational values their contributions and cares about their well-being". Persepsi dukungan organisasi dirasakan mencerminkan sejauh mana karyawan percaya bahwa nilai-nilai organisasi kontribusi mereka dan peduli tentang kesejahteraan mereka. Menurut Stephen P. Robbins, Timothy A. Judge (2013:76) mendefinisikan POS sebagai berikut, "perceived organizational support is the degree to which employees believes the organization values their contribution and cares about their well-being (for example, an employee believes his organization would accommodate him if he had a child care problem or would forgive an honest mistake on his part". Persepsi dukungan organisasi adalah derajat sejauh mana karyawan percaya bahwa organisasi menghargai kontribusi karyawan dan peduli terhadap kesejaterahan karyawan (sebagai contoh: karyawan percaya organisasi akan membantunya, jika ia memiliki masalah atau organisasi memaafkan karyawan jika ia melakukan kesalahan yang tidak sengaja). Menurut Jennifer M. George, Gareth Jones (2012:267) mendefinisikan dukungan organisasi sebagai berikut, "organizational support is the extent to which an organization cares about he well-being of its members, listens to their complaints, tries to help them when they have a problem and treats them fairly". Dukungan organisasi adalah sejauh mana organisasi peduli terhadap kesejaterahan anggota-anggotanya, mendengarkan keluhan-keluhan mereka, mencoba membantunya ketika mereka mempunyai suatu masalah dan memperlakukan anggotanya secara adil. Dukungan organisasi mempunyai pengaruh sangat besar bagi persepsi anggotanya dan merasa berkewajiban untuk berbuat yang terbaik bagi organisasinya. Perasaan kewajiban pada anggota organisasi ini di wujudkan dalam perilaku dalam bekerja yang mendukung pencapaian strategi dan tujuan organisasi.

Berdasarkan beberapa deskripsi konsep yang dipaparkan di atas, maka dapat disintesiskan persepsi dukungan organisasi adalah kepedulian organisasi tempat bekerja dalam menghargai kontribusi pegawai dan peduli akan kesejaterahaannya dengan indikator perhatian terhadap pegawai, pemenuhaan kebutuhan, tanggapan terhadap keluhan. 


\section{Kepribadian}

Psikologi mencoba untuk mengidentifikasi keunikan individu dan untuk mengukur dan memahami perbedaan antara individu yang didasarkan pada konsep kepribadian. Menurut Suzanne C. de Janasz, Karen O. Dowd, Beth Z. Schneider (2012:8), "personality describe the relatively stable of characteristic, tendencies, and temperaments that have a been formed by heredity and by social, cultural and environmental factors". Kepribadian menggambarkan relatif stabil karakteristik, kecenderungan, dan temperamen yang merupakan dibentuk oleh faktor keturunan dan faktor sosial, budaya dan lingkungan. Ricky W. Grifin, Gregory Moorhead (2014:66) mendefinisikan kepribadian sebagai berikut, "personality is the relatively stable set of psychological attributes that distinguish one person from another". Kepribadian merupakan himpunan atribut psikologis yang stabil yang membedakan satu dengan lainnya. Selanjutnya Robert P. Vecchio (2006:26), "personality can be defined as the relatively enduring individual traits and dispositions that form a pattern distinguishing one person from all others". Kepribadian dapat didefinisikan sebagai ciri-ciri individu yang relatif abadi dan disposisi yang membentuk pola yang membedakan satu orang dari yang lain.

James L.Gibson, John M. Ivancevich,James H. Donnelly, Jr, Robert Konopaskeh (2012:102) menjelaskan, "personality a stable set of characteristics and tendencies that determine commonalities and difference in people behavior". Kepribadian adalah satu set karakteristik dan kecenderungan yang menentukan persamaan dan perbedaan perilaku orang. Gordon Allport yang dikutip oleh Stephen P. Robbins, Timothy A.Judge (2015:154) mendefinisikan kepribadian sebagai berikut, "personality is the dynamic organization within the individual of those psychophysical systems that determine his unique adjustment to his environment". Kepribadian adalah organisasi yang dinamis dalam diri individu dari sistem-sistem psikofisik yang menentukan penyesuaian yang unik terhadap lingkungan. Steven McShane, Mara Olekalns, Tony Travaglione (2013:43) mendefinisikan kepribadian sebagai berikut, "personality is the relatively enduring pattern of thoughts, emotions and behaviors that characterize a person, along with the psychological process behind those characteristics". Kepribadian adalah pola yang relatif abadi pikiran, emosi, dan perilaku yang menjadi ciri seseorang, bersama dengan proses psikologis di balik karakteristik.

Dari penjelasan para ahli di atas, maka dapat disintesiskan, kepribadian adalah karakter seseorang yang dinamis dan terintegrasi yang termanifestasi dalam cara berpikir, merasakan dan berindak secara unik dan stabil yang mencirikan tanggapan seseorang terhadap situasi yang meliputi faktor-faktor kepribadian yaitu kesungguhan, keramahan, keterbukaan terhadap pengalaman, ekstraversi dan neuroticiem.

\section{METODE PENELITIAN}

Penelitian ini menggunakan metode survey dengan teknik analisis jalur (path analys) Data penelitian ini dikumpulkan dengan cara memilih sampel dalam populasi. Populasi terjangkau dalam penelitian ini adalah seluruh guru SD Islam Al Azhar di Jakarta Timur yang berjumlah 215 guru. Dan perhitungan dengan menggunakan slovin, maka di peroleh jumlah sampel sebanyak guru yang dijadikan sampel frame dalam penelitian ini. Teknik pengumpulan data yang digunakan untuk penelitian ini adalah kuesioner. Selanjutnya dilakukan uji coba intrumen untuk menentukan butir-butir instrumen yang valid dan reliabel. Teknik analisis data dilakukan dengan statistika 
deskriptif dan statistika inferensial dengan terlebih dahulu melakukan uji prasyarat analisis yaitu normalitas populasi dan analisis regresi.

\section{HASIL PENELITIAN DAN PEMBAHASAN}

\section{Pengaruh persepsi dukungan organisasi terhadap kepuasan kerja.}

Dari hasil pengujian hipotesis pertama dapat disimpulkan bahwa terdapat pengaruh langsung positif persepsi dukungan organisasi terhadap kepuasan kerja dengan nilai koefisien korelasi sebesar 0,359 dan nilai koefisien jalur sebesar 0,288. Ini memberikan makna persepsi dukungan organisasi berpengaruh langsung terhadap kepuasan kerja.

Hasil penelitian ini senada dengan pendapat beberapa ahli di antaranya adalah Stephen P. Robbins (1996:150), "perceived organization support menyatakan bahwa, "people get more than just money, or achievement from their job". Orang mendapatkan lebih dari sekedar uang, atau prestasi dari pekerjaan mereka. Menurut Arius (2008:97), "influence of leader-member exchange, perceived organizationa support, papua ethnic culture and organizational citizenship behavior toward employee performance of workers in papua provincial secretary office"The statement shows that employees do not just get money or appreciation of his work. In most employees, the work also membuthkan social interaction, which can scaling job satisfaction. Pernyataan tersebut menunjukkan bahwa para pegawai tidak hanya mendapatkan uang atau penghargaan dari pekerjaannya. Pada kebanyakan pegawai juga membutuhkan interaksi sosial, yang dapat meningkatkan kepuasan kerja. Jason A. Colquitt, Jeffery A. Lepine, Michael J. Wesson (2015:82) menjelaskan, "perceived organizational support reflects the degree to which employees believe that the organizational values their contributions and cares about their well-being". Schermerhorn et.al (2011:72), kepuasan kerja merupakan sebuah sikap, "job satisfaction, an attitude reflecting a person's positive and negative feelings toward a job, co-workers and the work environment". Kepuasan kerja sebuah sikap yang mencerminkan perasaan positif atau negatif dari seseorang terhadap pekerjaan, rekan kerja dan lingkungan kerja. Kepuasan kerja merupakan salah satu faktor yang harus diperhatikan dalam upaya meningkatkan kinerja pegawai. Menurut John R. Schermerhorn (2011:388) mendefinisikan kepuasan kerja, "job satisfaction is the degree to which an individual feels positive or negative about various aspcets of work". Kepuasan kerja adalah sejauh mana seseorang merasa positif atau negatif tentang berbagai aspek pekerjaan. Pendapat yang serupa dikemukakan oleh Stephen P. Robbins, Timothy A. Judge (2013:108) berpendapat bahwa, "job satisfaction is a positive feeling about a job resulting from an evaluation of its characteristics is clearly broad". Kepuasan kerja adalah perasaan positif tentang pekerjaan sebagai hasil dari evaluasi pada suatu karakter adalah jelas digambarkan.

Jason Colquitt Jeffery A. Lepine and Michael J. Wesson (2015:98) menyatakan bahwa, "job satisfaction is defined as a pleasurable emotional state resulting from the appraisal of one's job or job experiences". Kepuasan kerja didefinisikan sebagai keadaan emosional yang menyenangkan yang dihasilkan dari penilaian dari pekerjaan atau pengalaman kerja. Persepsi dukungan organisasi dapat dirasakan mencerminkan sejauh mana pegawai percaya bahwa nilai-nilai organisasi akan berkontribusi dan peduli tentang kesejahteraan mereka.

\section{Pengaruh kepribadian terhadap kepuasan kerja.}


Dari hasil pengujian hipotesis kedua dapat disimpukan bahwa terdapat pengaruh langsung positif kepribadian terhadap kepuasan kerja dengan nilai koefisien korelasi sebesar 0,348 dan nilai koefisien jalur sebesar 0,273. Ini memberikan makna kepribadian berpengaruh langsung terhadap kepuasan kerja.

Hasil penelitian ini senada dengan pendapat beberapa ahli di antaranya adalah James L. Gibson, James H. Donnelly, JR, John M. Ivancevich, Robert Konopaske (2012:111), "extraversion-introversion. The degree to which a person is sociable, gregarious and assertive versus reserved, quiet and timid. Research has been reported that extroverted people tend to perform well in sales and management jobs. Do better in training programs and have higher levels of overall job satisfaction". Extraversion-introversi. Sejauh mana seseorang bergaul, suka berteman dan tegas terhadap pendiam, tenang dan pemalu. Penelitian telah melaporkan bahwa orang-orang ekstrover cenderung tampil baik dalam penjualan dan pekerjaan manajemen. Berbuat lebih baik dalam program pelatihan dan memiliki tingkat kepuasan kerja secara keseluruhan. Suzanne C. de Janasz, Karen O. Dowd, Beth Z. Schneider (2012:8) menjelaskan, "personality describe the relatively stable of characteristic, tendencies, and temperaments that have a been formed by heredity and by social, cultural and environmental factors". Kepribadian menggambarkan relatif stabil karakteristik, kecenderungan, dan temperamen yang merupakan dibentuk oleh faktor keturunan dan faktor sosial, budaya dan lingkungan. Ricky W. Grifin, Gregory Moorhead (2014:66) mendefinisikan kepribadian sebagai berikut, "personality is the relatively stable set of psychological attributes that distinguish one person from another". Kepribadian merupakan himpunan atribut psikologis yang stabil yang membedakan satu dengan lainnya. Selanjutnya Robert P. Vecchio (2006:26) menjelaskan, "personality can be defined as the relatively enduring individual traits and dispositions that form a pattern distinguishing one person from all others". Kepribadian dapat didefinisikan sebagai ciri-ciri individu yang relatif abadi dan disposisi yang membentuk pola yang membedakan satu orang dari yang lain.

James L.Gibson, John M. Ivancevich,James H. Donnelly, Jr, Robert Konopaskeh (2012:102) menjelaskan, "personality a stable set of characteristics and tendencies that determine commonalities and difference in people behavior". Kepribadian adalah satu set karakteristik dan kecenderungan yang menentukan persamaan dan perbedaan perilaku orang. John R. Schermerhorn (2011:388) mendefinisikan kepuasan kerja, "job satisfaction is the degree to which an individual feels positive or negative about various aspcets of work". Kepuasan kerja adalah sejauh mana seseorang merasa positif atau negatif tentang berbagai aspek pekerjaan. Dengan demikian, keakuratan dalam kepribadiaan seseorang akan mengakibatkan peningkatan kepuasan kerjanya.

\section{Pengaruh perspesi dukungan organisasi terhadap kepribadian.}

Dari hasil pengujian hipotesis ketiga dapat disimpulkan bahwa terdapat pengaruh langsung positif persepsi dukungan organisasi terhadap kepribadian dengan nilai koefisien korelasi sebesar 0,261 dan nilai koefisien jalur sebesar 0,261. Ini memberikan makna persepsi dukungan organisasi berpengaruh langsung terhadap kepribadian.

Hasil penelitian ini senada dengan pendapat beberapa ahli di antaranya adalah Kwahaja Imran, Mehvish Sher (2014:33) dalam risetnya yang berjudul perceived organizational support, pay satisfaction and supervisor satisfaction impact on career satisfaction, "support organization has enormous influence for the perception of its members and feel obliged to do what is best for the organization. Feelings of obligation on members of this organization were embodied in the behavior of the work that supports the achievement of the organization's 
strategies and objectives". Dukungan organisasi mempunyai pengaruh sangat besar bagi persepsi guru dan merasa berkewajiban untuk berbuat yang terbaik bagi organisasi sekolah. Perasaan kewajiban pada guru, organisasi ini di wujudkan dalam perilaku dalam bekerja yang mendukung pencapaian strategi dan tujuan organisasi. Stephen P. Robbins, Timothy A. Judge (2013:76) mendefinisikan POS, yaitu, "perceived organizational support is the degree to which employees believes the organization values their contribution and cares about their well-being ( for example, an employee believes his organization would accommodate him if he had a child care problem or would forgive an honest mistake on his part". Persepsi dukungan organisasi adalah derajat sejauh mana karyawan percaya bahwa organisasi menghargai kontribusi karyawan dan peduli terhadap kesejaterahan karyawan (sebagai contoh: karyawan percaya organisasi akan membantunya, jika ia memiliki masalah atau organisasi memaafkan karyawan jika ia melakukan kesalahan yang tidak sengaja). Dengan demikian kekuatan dukungan organisasi yang dirasakan pegawai, maka akan mengakibatkan keakuratan kepribadian seseorang.

\section{PENUTUP}

Kesimpulan: 1)Persepsi dukungan organisasi berpengaruh langsung positif terhadap kepuasan kerja. Artinya peningkatan dukungan organisasi kepada guru secara langsung akan meningkatkan kepuasan guru SD Islam al Azhar di Jakarta Timur. 2)Kepribadian berpengaruh langsung positif terhadap kepuasan kerja. Artinya kepribadian yang baik di miliki guru akan meningkatkan kepuasan kerja guru selama di sekolah. 3)Persepsi dukungan organisasi berpengaruh langsung positif terhadap kepribadian. Artinya peningkatan dukungan organisasi kepada guru akan berdampak kepada kepribadian setiap guru dan secara tidak langsung akan berpengaruh kepada kepuasan kerja guru. Saran: 1) Bagi kepala sekolah SD Islam Al Azhar di Jakarta Timur, untuk membantu menikatkan dukungan organisasi kepada para guru dengan berbagai cara di antaranya, memperhatikan setiap kebutuhan guru, memperhatikan setiap kesulitan guru baik dalam mengajar ataupun tidak. 2)Bagi guru SD Islam Al Azhar di Jakarta Timur, untuk terus meningkatkan kemampuan diri guru dalam rangka mempersiapkan standar kinerja yang jauh lebih baik lagi. 3) Bagi peneliti lain, dapat dijadikan bahan rujukan dalam rangka peneliti lebih lanjut terkait dengan persepsi dukungan organisai dan kepribadian terhadap kepuasan kerja.

\section{DAFTAR RUJUKAN}

Colquitt, Jason A., Jeffery A. Lepine and Michael J. Wesson, Organizational Behavior Improving Performance and Commitment in The Workplace. New York: McGraw-Hill, 2015.

George, Jennifer M. and gareth jones. understanding and managing organizational behavior. new jersey: pearson education,inc, 2012.

Gibson, James L., James H.Donnelly, JT, John M. Ivancecivh, Robert Konopakse, Organizational Behavior, structure, processes Fourteenth Editions. New York: McGraw-Hill, 2012. 
Greenberg, Jerald dan Robert A. Baron. Behavior in Organization:ninth edition. New Jersey: Pearsin Prentice Hall,2008.

Grifin, Ricky W. Gregory Moorhead, Organizational Behavior Managing people and Organization 11 edition. South-Westren: Cengange Learning, 2014.

Kinicki, Angelo, Brian K. Wiliams, Management a Practical Introduction. New York: McGraw-Hill,2011.

Laurie J. Mullins, Management and Organizational Behaviour Ninth edition. New Jersey: Pearson Prentice Hall, 2010. 